\title{
Directions in dragonfly applied ecology and conservation science
}

\author{
Jason T. Bried ${ }^{1,6}$, Christopher Hassall ${ }^{2,7}$, John P. Simaika ${ }^{3,8}$, Jeffrey D. Corser ${ }^{4,9}$, \\ and Jessica Ware ${ }^{5,10}$ \\ ${ }^{1}$ Department of Integrative Biology, Oklahoma State University, Stillwater, Oklahoma 74078 USA \\ ${ }^{2}$ School of Biology, University of Leeds, Leeds LS2 9JT UK \\ ${ }^{3}$ Department of Conservation Ecology and Entomology, Faculty of AgriScience, Stellenbosch University, Private Bag X1 Matieland \\ 7602, South Africa \\ ${ }^{4}$ New York Natural Heritage Program, State University of New York College of Environmental Science and Forestry, Albany, \\ New York 12233 USA \\ ${ }^{5}$ Department of Biological Sciences, Rutgers University, Newark, New Jersey 07102 USA
}

Dragonflies and damselflies (Odonata) provide a tractable focal group and model system for addressing new and emerging challenges in applied ecology and conservation science (Samways 2008). However, the study of dragonflies and damselflies (odonatology) has not been focused on such matters until fairly recently, a fact illustrated by selected conference proceedings and journal special issues that have appeared only in the past 20 years (Corbet et al. 1995, Clausnitzer and Jödicke 2004, Rivera 2006, Ott 2010). Contributions in our series build on these previous collections and on a strong foundation of fundamental ecological and evolutionary research on odonates (Corbet 1999, Córdoba-Aguilar 2008).

Our series emerged from a symposium at the 2013 annual meeting of the Society for Freshwater Science in Jacksonville, Florida, USA. Presenters at that session highlighted some of the current directions in dragonfly conservation science and the recent advances linking odonatology to freshwater applications and conservation. The symposium and series integrate diverse topics, perspectives, and geographic representation along with experience levels ranging from graduate students and post docs to some of the most prolific researchers in odonatology. Our goal was to showcase odonates both for their utility and as worthy study subjects in their own right, and Freshwater Science has a strong history of presenting special series with freshwater focal groups (e.g., Helms et al. 2013).

The series begins with a review by Bried and Samways (2015) of the major themes and study characteristics in the primary literature. They identified several nonexclusive areas of applied/conservation research involving odonates: 1) model taxa, 2) tools and indicators, 3) odonatecentered work, and 4) methodological issues and develop- ment. All papers in the series fall into at least 1 of these categories. The authors also proposed the term 'applied odonatology' and suggested some directions for advancing this field.

Odonates are of increasing interest in applied research as potential tools, indicators, and model taxa (Bried and Samways 2015). For example, they are used in studies of ecological responses to disturbance and for assessing environmental change. Stoks et al. (2015) reviewed studies in which damselflies were used as model organisms in aquatic toxicology and explored the delayed effects of contaminants, synergistic interactions with biota, and vulnerability under climate change. They found that delayed fitnessrelated effects during the larval stage may carry over to the adult stage, and natural stressors (predation risk, extreme temperature) can magnify the effects. They called for spatially explicit risk assessment and conservation tools to address these issues. Hassall (2015) compared and contrasted the spatial and temporal responses of a range of vertebrate and invertebrate taxa, including odonates, to climate change. Among candidate taxa for indicating environmental change at a macro scale, Odonata appear particularly well suited because biological records for this group are extensive, and odonates show consistent phenological and distributional responses to increasing environmental temperature. Harabiš and Dolný (2015) revealed a disparity between natural disturbance and ecological management. They presented a case where restoration may not be achieving the desired or expected results. Reclamation of minesubsidence pools did not promote sensitive species or those associated with early successional habitats.

The largest share of applied research involving odonates is odonate-centered and includes emerging fields,

E-mail addresses: ${ }^{6}$ bried@okstate.edu; ${ }^{7}$ c.hassall@leeds.ac.uk; ${ }^{8}$ simaikaj@sun.ac.za; ${ }^{9}$ jdcorser@esf.edu; ${ }^{10}$ jware@amnh.org 
such as conservation/landscape-scale genetics, and more traditional topics like conservation status assessments (Bried and Samways 2015). Two contributions in the series offer genetic insights for conservation planning. Monroe and Britten (2015) estimated genetically effective population sizes for Somatochlora hineana, the only odonate designated as federally endangered in the USA. They concluded that the species deserves its legal protection, and identified habitat quality and connectivity as key attributes to maintaining its population genetic diversity. LorenzoCarballa et al. (2015) surveyed populations at the range margin of the Red Listed damselfly Coenagrion mercuriale in northwestern France to better understand how landscape fragmentation is affecting its spatial genetic structure and diversity. Fragmentation has clearly limited gene flow among habitat patches in this naturally dispersallimited species.

White et al. (2015) completed a regional status ranking based on rarity factors, vulnerability of occupied habitats, relative change in range size, and degree of endemicity for the 228 odonate species known from the northeastern USA. They estimated that $18 \%$ of the fauna is imperiled and identified several priority habitat types for conservation. Termaat et al. (2015) analyzed the latest $\sim 20$-y trend for dragonflies in The Netherlands. Their study was motivated by increasing threats to aquatic systems and recent efforts to abate those threats and restore those systems. Recovery appeared to be taking place, but lotic and southern species showed a more positive trajectory than wetland and northern species. Habitat restoration, water-quality improvement, climate change, and species resilience may all be contributing to the recovery.

Methods development and evaluation is another important area of applied odonatology (Bried and Samways 2015). The prioritization framework proposed by White et al. (2015) could be used for other regions and taxa to guide multiscale conservation assessments. Termaat et al. (2015) used standardized and unstandardized (opportunistic) survey data for trends analysis and suggested that unstandardized surveys generally will provide greater statistical power because of the larger quantity of data points. A set of papers on species distribution models (highlighted below) also has important methods components.

Two articles in our series were focused entirely on issues related to methods, specifically to assessing local species residency. Bried et al. (2015) addressed the problem of differentiating resident (autochthonous) vs immigrant (allochthonous) species in standardized adult surveys at specific localities. They uncovered thresholds in adult survey information that reliably corresponded with emergence at the site, as calibrated by final exuviae (molted exoskeleton of F-0 nymphs). The resulting set of criteria may serve to maximize the utility of odonates in site applications, such as biomonitoring. Patten et al. (2015) explored whether predicted niches from species distribu- tion models differed with data type by using opportunistic point records of breeding evidence (tandem pairs, ovipositing females, recently emerged adults, exuviae) vs opportunistic point records without such evidence as model input. Models for breeding evidence revealed greater ecological specializations and narrower distributions than models for adults without evidence of breeding. Their results suggest that inclusion of breeding observations could improve the reliability of opportunistic data and species distribution models for conservation planning and monitoring.

The series closes with other papers that feature species distribution modeling, a widespread approach in ecology, biogeography, and conservation that is gaining momentum in applied odonatology. De Marco et al. (2015) modeled current distributions and predicted range shifts with respect to future deforestation in the Amazon, while Simaika and Samways (2015) did the same with respect to regional climate change and elevation range shifts in South Africa. De Marco et al. (2015) identified core and peripheral habitat for a rare forest-dependent dragonfly (Diastatops nigra) and concluded that deforestation is a more serious threat to the peripheral than the core populations. Simaika and Samways (2015) found that Afrotropical species with narrow elevation ranges are perhaps as vulnerable as stream specialists to regional climate change. Furthermore, although species richness is likely to remain similar across habitats, significant species replacement among communities is likely. The last paper is an in-depth review of species distribution models for odonates (Collins and McIntyre 2015). The authors discuss the various applications in odonatology and the limitations with respect to ecological realism, calling for greater appreciation of species requirements and finer-resolution analysis in future modeling efforts.

Our series offers a glimpse into the state-of-the-science of applied odonatology. The rapid growth in the use of odonates in an applied setting has been facilitated by the legacy of fundamental biology that has accumulated over the past century (summarized by Corbet 1999 and CórdobaAguilar 2008). This baseline knowledge, combined with the practical advantages inherent to the focal group (e.g., charismatic adult stage accessible to conservation practitioners and nonspecialists), makes the Odonata a tractable model system for applied ecologists and conservation scientists. We look forward to the continued growth of odonate research within applied ecology and conservation science, and expect this series to produce profitable collaborations by linking odonatology with emerging issues in the ecology and conservation of fresh waters.

\section{LITERATURE CITED}

Bried, J. T., A. M. Dillon, B. J. Hager, M. A. Patten, and B. Luttbeg. 2015. Criteria to infer local species residency in standardized adult dragonfly surveys. Freshwater Science 34:1105-1113. 
Bried, J. T., and M. J. Samways. 2015. A review of odonatology in freshwater applied ecology and conservation science. Freshwater Science 34:1023-1031.

Clausnitzer, V., and R. Jödicke (editors). 2004. Guardians of the watershed. Global status of dragonflies: critical species, threat and conservation. International Journal of Odonatology 7: 111-429.

Collins, S. D., and N. E. McIntyre. 2015. Modeling the distribution of odonates: a review. Freshwater Science 34:10441058.

Corbet, P. S. 1999. Dragonflies: behavior and ecology of Odonata. Cornell University Press, Ithaca, New York.

Corbet, P. S., S. W. Dunkle, and H. Ubukata (editors). 1995. Proceedings of the International Symposium on the Conservation of Dragonflies and their Habitats: Kushiro, Hokkaido, Japan, 13-15 August 1993. Japanese Society for Preservation of Birds, Kushiro, Japan. (Available from: WorldCat libraries database, www.worldcat.org)

Córdoba-Aguilar, A. (editor). 2008. Dragonflies and damselflies: model organisms for ecological and evolutionary research. Oxford University Press, Oxford, UK.

De Marco, P., C. C. Nóbrega, R. A. de Souza, and U. G. Neiss. 2015. Modeling the distribution of a rare Amazonian odonate in relation to future deforestation. Freshwater Science 34:1123-1132.

Harabiš, F., and A. Dolný. 2015. Odonates need natural disturbances: how human-induced dynamics affect the diversity of dragonfly assemblages. Freshwater Science 34:10501057.

Hassall, C. 2015. Odonata as candidate macroecological barometers for global climate change. Freshwater Science 34:10401049.

Helms, B., Z. J. Loughman, B. L. Brown, and J. Stoeckel. 2013. Recent advances in crayfish biology, ecology, and conservation. Freshwater Science 32:1273-1275.
Lorenzo-Carballa, M., S. Ferreira, A. M. Sims, D. J. Thompson, P. C. Watts, Y. Cher, V. Damoy, A. Evrard, W. Gelez, and C. Vanappelghem. 2015. Impact of landscape on spatial genetic structure and diversity of Coenagrion mercuriale (Zygoptera: Coenagrionidae) in northern France. Freshwater Science 34:1065-1078.

Monroe, E., and H. B. Britten. 2015. Single-sample estimation of effective population size in several populations of the endangered Hine's emerald dragonfly. Freshwater Science 34:1058-1064.

Ott, J. (editor). 2010. Monitoring climatic change with dragonflies. BioRisk 5:1-286.

Patten, M. A., J. T. Bried, and B. D. Smith-Patten. 2015. Survey data matter: predicted niche of adult vs breeding Odonata. Freshwater Science 34:1114-1122.

Rivera, A. C. (editor). 2006. Forests and dragonflies. $4^{\text {th }}$ WDA International Symposium of Odonatology, Pontevedra, Spain, July 2005. Pensoft Publishers, Sofia, Moscow.

Samways, M. J. 2008. Dragonflies as focal organisms in contemporary conservation biology. Pages 97-108 in A. CórdobaAguilar (editor). Dragonflies and damselflies: model organisms for ecological and evolutionary research. Oxford University Press, Oxford, UK.

Simaika, J. P., and M. J. Samways. 2015. Predicted range shifts of dragonflies over a wide elevation gradient in the southern hemisphere. Freshwater Science 34:1133-1143.

Stoks, R., S. Debecker, K. D. Van, and L. Janssens. 2015. Integrating ecology and evolution in aquatic toxicology: insights from damselflies. Freshwater Science 34:1032-1039.

Termaat, T., R. H. A. van Grunsven, C. L. Plate, and A. J. van Strien. 2015. Strong recovery of dragonflies in recent decades in The Netherlands. Freshwater Science 34:1094-1104.

White, E. L., P. D. Hunt, M. D. Schlessinger, J. C. Corser, and P. G. deMaynadier. 2015. Prioritizing Odonata for conservation action in the northeastern USA. Freshwater Science 34: 1079-1093. 